Document downloaded from:

http://hdl.handle.net/10251/141960

This paper must be cited as:

Broatch, A.; Novella Rosa, R.; Garcia Tiscar, J.; Gómez-Soriano, J. (04-2). Potential of dual spray injectors for optimising the noise emission of gasoline partially premixed combustion in a 2-stroke HSDI Cl engine. Applied Thermal Engineering. 134:369-378.

https://doi.org/10.1016/j.applthermaleng.2018.01.108

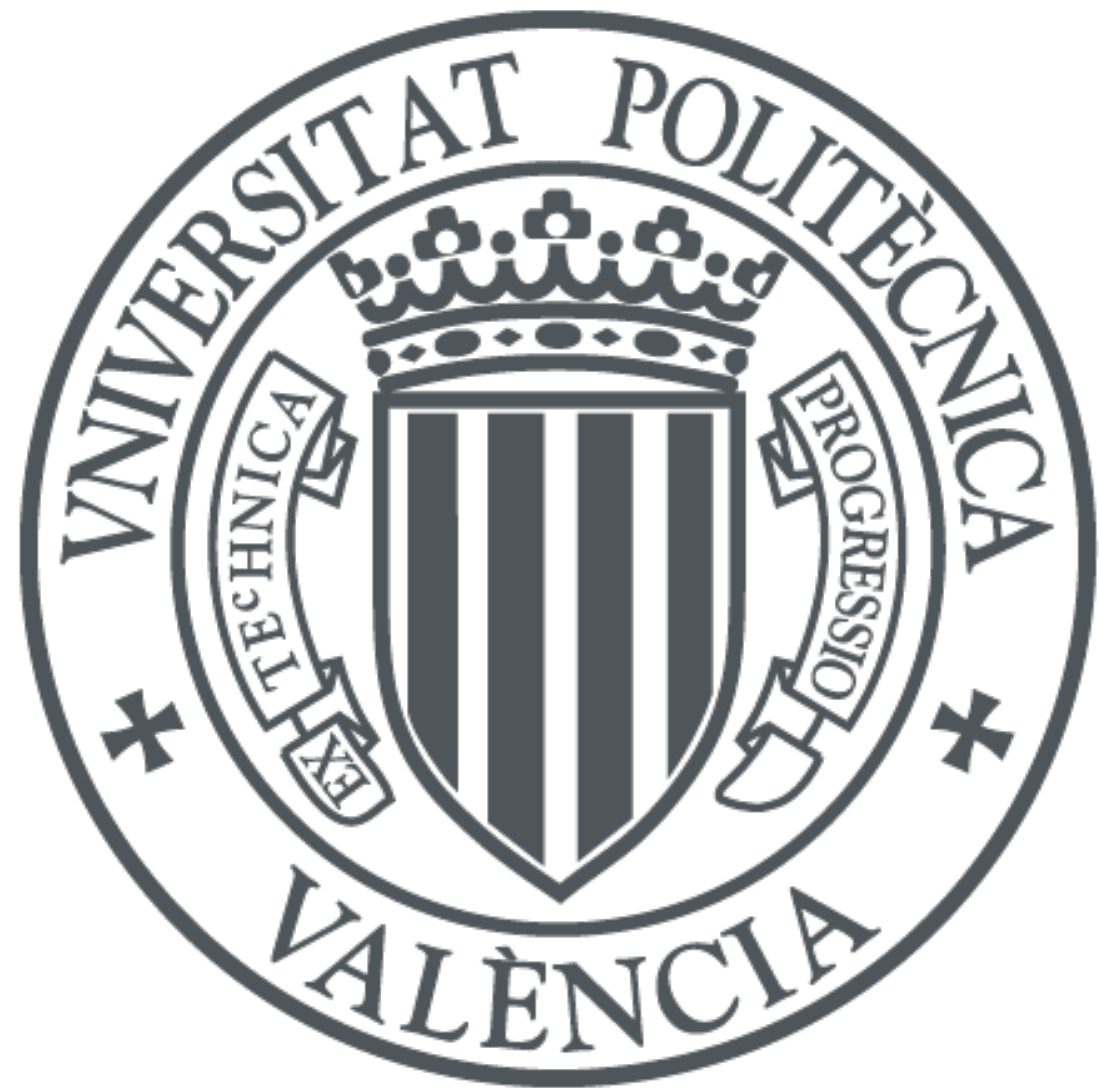

The final publication is available at

https://doi.org/10.1016/j.applthermaleng.2018.01.108

Copyright Elsevier

Additional Information 


\title{
Potential of dual spray injectors for optimising the noise emission of gasoline partially premixed combustion in a 2-stroke HSDI Cl engine
}

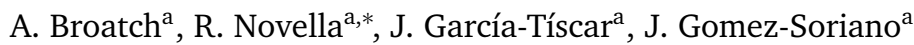 \\ ${ }^{a}$ CMT - Motores Térmicos, Universitat Politècnica de València, \\ Camino de Vera $s / n, 46022$ Valencia, Spain
}

\begin{abstract}
This paper evaluates the potential advantages of introducing a new injector concept with a dual set of orifices in a 2-stroke engine operating with gasoline partially premixed combustion (PPC gasoline), specially in terms of combustion noise reduction. The injector is based on a configuration with two concentric needle valves and dual actuators, which allows to switch among two independent crowns of holes. The first set of orifices is controlled by the primary needle valve while an additional needle valve manages the secondary holes crown. Moreover, both valves are coupled with the two actuators separately, providing enhanced selective control over injection with an extra degree of freedom. In this investigation, a combination of Computational Fluid Dynamics (CFD) simulations and the Design of Experiments (DoE) technique is proposed with the specific purpose of optimizing this new injector configuration. In addition to determining the most convenient design, this method is extremely useful to establish cause/effect relationships between the injection design parameters and their impact on the engine performance and emissions. Results show how this solution could increase the operating range of the PPC gasoline concept by improving the combustion stability while acoustic emissions are reduced.
\end{abstract}

Keywords: Gasoline PPC concept, 2-stroke engine, Dual spray injectors, Combustion noise, CFD, Acoustics

\section{Introduction}

Growth usually means success in the industry sector; it indicates a progressive business expansion and an appreciable increase of the produced incomes. However, excessive growth can lead to a reverse and undesired situation which compromises the existence of the group itself. For example, industrial activities and their derived tasks have caused a huge raise of environmental pollution during the last decade [1]. Likewise, population increase has conditioned healthy lives, decent work and equitable quality education for everyone.

The number of actions for searching an inclusive and sustainable development has significantly increased in recent years, becoming a topic of current interest in all society collectives. One such example is the United Nations Conference on Sustainable Development ${ }^{1}$, which produced a new impulse for achieving sustainable development. This conference, known as Rio+20, took place under the catchphrase the future we want with the aim of developing a set of Sustainable Development Goals (SDGs) [2]. Governments have consequently introduced new regulations, policy, taxes and incentives to achieve these new requests.

This situation has resulted in several consequences and business opportunities for the engineering industry. For instance, ensuring access to affordable and clean energy, build-

\footnotetext{
*Corresponding author. Tel.: +34 9638796 50, fax: +34 9638776 59, email: rinoro@mot.upv.es

${ }^{1}$ Rio de Janeiro, Brazil on 20-22 June 2012.
}

ing industry infrastructure, innovation strategies and combating climate change are some of the fields in which engineering activities are being expanded.

Although the effects of these measures are still negligible in most of the sectors, they are more evident in segments with high competitive markets. Automotive industry, for example, is experiencing revolutionary transition from fuel propelled cars to electric vehicles [3]. Indeed, hybrid cars are widely established in the European urban environment because of their advantages in terms of fuel consumption and pollutant emissions.

In the face of these challenges, numerous research efforts are currently focused on facing new hybrid system requirements. Engine manufacturers in collaboration of public institutions ${ }^{2}$ have developed interesting technologies which involve new engine and combustion concepts.

One of the most interesting combustion modes in the search of higher efficiency and cleaner exhaust emissions is the gasoline partially premixed combustion (PPC) $[4,5]$. It operates with partially premixed charges, between entire premixed and complete diffusive conditions. These particular conditions allow to reach very low emissions of both nitrous oxides $\left(\mathrm{NO}_{\mathrm{x}}\right)$ and particulate matter $(\mathrm{PM})$ while the engine efficiency is maintained or even improved [6].

\footnotetext{
${ }^{2}$ European Union sponsored relevant programs such as POWERtrain of FUture Light-duty vehicles (POWERFUL) and REal World Advanced Technologies foR Diesel Engines (REWARD) projects in the framework of sustainable surface transport.
} 
There is however an important drawback of this combustion mode: the operating range. Contrarily to the conventional diesel combustion (CDC), the injection alone does not guarantee ignition inside the chamber. Here the local thermodynamic conditions play a determinant role, given that slightly differences in the temperature and mixing conditions can lead to a very different combustion phasing. Therefore, the operation range between a high-sharp combustion (knock) and a unstable combustion (misfire) is extremely reduced and not accurately controlled. Nonetheless, a new engine concept based on a 2-stroke operating cycle [7] has demonstrated how this load range can be enlarged by managing the local charge conditions through the settings of the gas exchange process (GEP) or air management phase [6].

However, the noise linked to this particular mode of combustion compromises the compliance with future and even current legislations on noise levels, becoming a critical aspect which limits its implementation in automotive applications. The customers' sense of comfort is strongly affected by how they perceive the engine noise. Therefore, the engine noise perception can drastically condition the user purchasing decision. As a consequence, current research efforts are focused on developing new technologies which would allow to introduce this concept, specially in terms of combustion noise reductions and sound quality improvements $[8,9]$.

In the past, several studies were focused on determining which are the most influential combustion-related parameters in the perceived noise level and also in the sound quality. These studies resulted in a methodology for obtaining the transfer function between the noise source and the external acoustic field through in-cylinder pressure and free-field microphone measurements. The unsteady nature of the pressure field inside the combustion chamber demands multiple measurements points for its reconstruction [10]. Therefore, most authors prefer to use numerical simulations to assess the noise sources and to shed some light about the unsteady pressure field within the chamber, instead of performing complex and expensive engine modifications [11].

Nowadays, the increase in computational power coupled to the development of reacting flow codes allows simulating the combustion process, thus contributing to the understanding of the combustion dynamics and its effects on efficiency and pollutants production $[12,13]$. The maturity of these methods has opened new ways to explore the incylinder pressure field. Indeed, a recent investigation [14] has determined the main causes of the high combustion noise levels observed during the PPC gasoline operation. It demonstrated that the main contribution to the overall noise radiated by the engine comes from the maximum pressure rise rate connected to the premixed combustion.

Other researchers $[15,16]$ have evinced a trade-off between combustion noise y combustion efficiency when the combustion law is managed through a multiple injection strategy [17]. Moreover, a further step was taken in a previous publication [18], where the same research group analyzed the combustion process when the configuration of the injector is modified. They show the benefits of using an injector with a high number of orifices and a small included spray angle in the combustion efficiency. This configuration reduces the spray penetration and, therefore, it minimizes the liquid fuel impingement during early and long injections. In contrast, the spray-bowl matching worsening in late injections decreases the efficiency and increases PM emissions. In these circumstances, a configuration with a lower number of orifices and higher included angle can help to improve the spray-bowl matching, thus minimizing pollutant and noise emissions. Despite the improvement in terms of combustion efficiency and pollutant emissions, the optimization of a conventional injector does not allow an accurate control of the reactivity of the charge through the operation settings, thereby it still compromises other important aspects such as noise emissions or knocking combustion.

This paper explores the potential benefits of developing a combustion system able to combine both injector configurations described above. That is, to use the optimum configuration for each injection event. A possible physical implementation of such a system is the injector proposed by Perr [19], featuring dual actuators that allow switching between two sets (crowns) of orifices. The first actuator is connected to the first needle valve associated with a first set of injector orifices (crown 1), while the second actuator controls an additional concentric needle valve associated to a second set of orifices (crown 2). This is the configuration that will be considered in this study.

Since the proposed configuration would increase the complexity and therefore the cost of the injection system in production vehicles, the improvement of the combustion system investigated in this paper would need to be weighted against the manufacturing difficulty and the impact of the increased cost, aspects which are understandably beyond the scope of this work.

This configuration adds supplementary degrees of freedom to the intricate engine system, enlarging the number of parameters to be inspected. Thus, it demands to explore additional techniques for the identification of the optimizing paths in the configuration design. One of the most used methods for this purpose is the statistical approach known as Design of Experiments (DoE). This technique, coupled with the Response Surface Method (RSM), has been traditionally applied to multiple engineering design processes $[20,21]$ in order to establish cause-effect relationships between the influencing factors and their response.

In this framework, the objective of this investigation is to examine the advantages of employing a dual actuators injector in a 2-stroke compression ignition (CI) engine operated with the gasoline PPC concept. It is shown how this combustion system configuration can decrease the combustion noise while the efficiency losses are restricted. Furthermore, guidelines have been established for optimising the system configuration. 
Table 1: Specifications of the real engine being modelled and results from the injection system characterization

\begin{tabular}{ll}
\hline Engine type & 2-stroke HSDI CI \\
\hline Number of cylinders & 1 \\
Displacement & $365 \mathrm{~cm}^{3}$ \\
Bore - Stroke & $0.076-0.0805 \mathrm{~m}$ \\
Connecting rod length & $0.143 \mathrm{~m}$ \\
Compression ratio (geom.) & $17.8: 1$ \\
Compression ratio (effective) & From 13.0:1 to 8.8:1 \\
Number of valves & 2 intake and 2 exhaust \\
Injection system & Delphi DFI1.5 common rail \\
Injector nozzle design & $148^{\circ}-8$ holes $-90 \mu \mathrm{m}$ \\
Maximum injection pressure & $110 \mathrm{MPa}$ \\
\hline
\end{tabular}

\section{Experimental setup}

The experimental data needed for the validation of the CFD model was obtained from the same experimental configuration used in previous studies $[6,22]$. The engine is a single-cylinder research version of a 2-stroke high speed direct injection (HSDI) CI engine with poppet valves scavenge loop. Table 1 summarizes the main engine specifications and injection system characteristics.

The engine is equipped with a common rail fuel injection system, which grants a maximum rail pressure of $110 \mathrm{MPa}$ using gasoline fuel. The injector configuration has 8 orifices with a $90 \mu \mathrm{m}$ nozzle diameter and an included spray angle of $148^{\circ}$. The piston bowl geometry of conventional CI design with an open bowl geometry provided a geometric compression ratio of 17.6. The cylinder head shown in Fig. 1 has a singular design in order to optimize the scavenging of burnt gases. This particular design guides the fresh charge along the cylinder wall and towards the piston, thus avoiding the direct path between the intake and exhaust ports [23].

The valves timing control relies on a hydraulic cam-driven Variable Valve Timing (VVT) system. This system can modify the air management specifications in order to set the overlap period between the intake and exhaust and to adapt the effective compression ratio.

The engine was assembled in a completely instrumented test cell equipped with all auxiliary devices required for engine operation. The boost conditions are simulated with an external compressor which supplied the intake air. The exhaust back-pressure originated by the turbine was reproduced by means of a throttle valve located downstream of the exhaust settling chamber. The installation also included independent water and oil cooling circuits, and an additional exhaust gas recirculation (EGR) system to provide arbitrary levels of cooled exhaust gas.

The in-cylinder pressure was measured with a Kistler 6061B pressure transducer placed between the intake and exhaust valves opposite the glow plug location. Measurements of chemical exhaust gas elements and the EGR rate are obtained with an Horiba MEXA-7100 DEGR gas analyzer. The FSN (filter smoke number) is measured using an AVL 415 Smokemeter and soot emissions are later estimated [24].

High frequency signals were sampled at $45 \mathrm{kHz}$ using a dedicated acquisition system and recorded during 100 engine cycles. This sampling frequency ensure a free-aliasing bandwidth similar to the human hearing domain $-20 \mathrm{~Hz}$ to $20 \mathrm{kHz}$ - according to Nyquist's criterion [25].

\section{Numerical methodology}

In this section, the numerical methodology followed during this investigation is described in detail. First, the CFD model of the engine is specified. Second, the techniques used for obtaining additional validation parameters are explained. Finally, the validation methodology is briefly described.

\subsection{Numerical model setup}

A numerical model of the engine was build in the commercial CFD platform CONVERGE [26]. The model configuration is based on previous works $[14,18]$. The numerical domain includes the cylinder geometry, intake and exhaust ports and it consists of a structured mesh of hexahedrons with a base cell size of $3 \mathrm{~mm}$. This configuration allows performing full engine cycles simulations, comprising the GEP, the compression and combustion phases.

Several grid refinements were added to the original mesh size in order to improve the accuracy in zones in which the physical and chemical phenomena are particularly complex. As seen in Fig. 1, the refinement is applied to the combustion chamber and ports walls, in the spray regions and in the whole chamber during the combustion. Moreover, the code automatically increases the spatial resolution in regions in which the gradients of velocity and temperature are considerable, by means of an adaptive mesh refinement algorithm (AMR). Hence, the number of cells varied between $1.5 \times 10^{6}$ and $0.5 \times 10^{6}$ depending on the simulation stage.

The calculation time was optimized by a dynamic time step strategy and two Courant number definitions:

$$
\begin{aligned}
& \mathrm{C}_{\mathrm{u}}=u \frac{\Delta t}{\Delta x} \\
& \mathrm{C}_{\mathrm{c}}=c \frac{\Delta t}{\Delta x}
\end{aligned}
$$

The time step is therefore estimated by the maximum local velocity registered at the smallest cells in the domain at every calculation interval. For the GEP, compression and injection stages, the flow velocity $(u)$ was considered in order to obtain the time step, while the speed of sound (c) was used instead during the combustion phase.

The flow governing equations were numerically solved with the finite volume method and with a second-order accurate scheme. The renormalization group (RNG) $k-\varepsilon$ model [27] coupled with the heat transfer approach proposed by Angelberger et al. [28] was used for modelling the turbulent flow features. This approach has proven to accurately 


\section{Mesh at TDC}

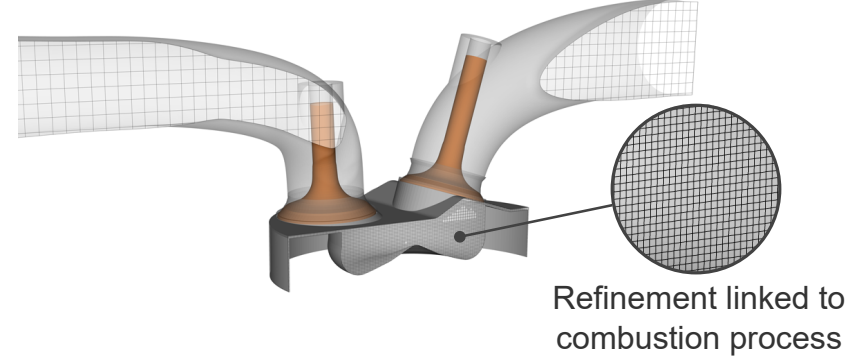

Mesh at IVC

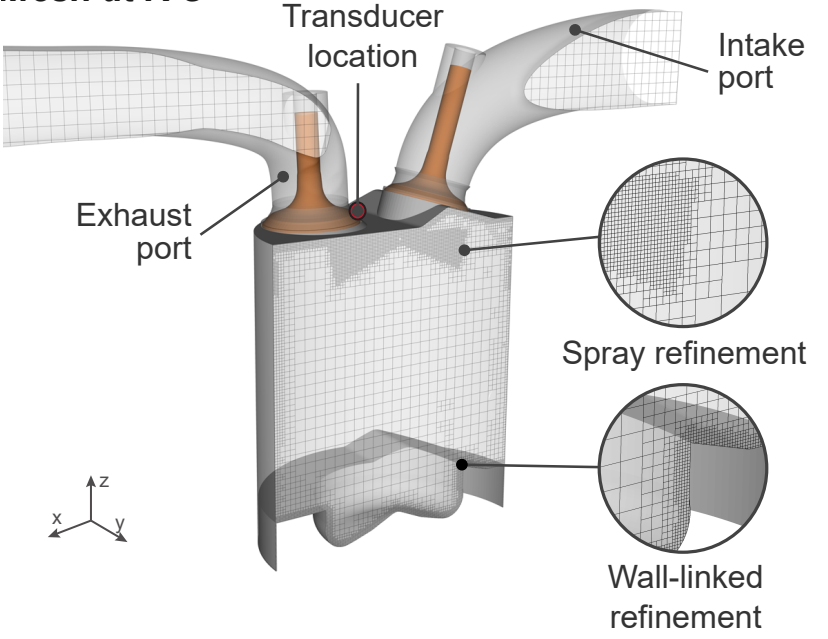

Figure 1: Computational domain and mesh characterization of the engine architecture at different calculation phases.

reproduce the in-cylinder pressure field oscillations over a wide range of operation conditions and combustion regimes $[29,30]$. Therefore, the macroscopic oscillations of the pressure waves due to the autoignition of the premixed fuel-air blend are still successfully reproduced, even if the local fluctuation components of the Navier-Stokes equations are neglected.

Fuel injection was modelled by the standard Discrete Droplet Model (DDM) [31] coupled to the Kelvin-Helmholtz Rayleigh-Taylor (KH-RT) model [32] for the assessment of the physical properties of the spray. The injection rate was obtained from the injection characterisation in order to provide the most realistic spray features for the CFD calculations. During this procedure, mass flow rate and spray momentum flux were measured in dedicated test rigs in similar engine test conditions for approximate the injection rate [33] .

The code approaches the detailed chemical kinetics through a direct integration of the surrogate fuel chemical mechanism by means of the SAGE (detailed transient chemistry solver) solver [34]. The gasoline fuel chemistry was characterized by a chemical mechanism which corresponds to a Primary Reference Fuel (PRF) blend of n-heptane (5\%) and iso-octane (95\%). The PRF oxidation was obtained from an adapted reaction mechanism derived from the ECR-Multichem mechanism [35].
Regarding emissions, soot formation an oxidation mechanisms were approached by the Hiroyasu's model [36] whereas the nitrous oxides production was predicted with the Zel'dovich mechanism including $\mathrm{N}_{2} \mathrm{O}$ and $\mathrm{NO}_{2}$ paths.

Although thermodynamic conditions can significantly change during the combustion when the injection configuration is modified, they are not excessively altered at the end of the GEP. Thus, the GEP simulation was only calculated for the reference operating conditions and extrapolated for all closed cycle simulations. This simplification reduces the computational time and provides more realistic flow conditions for combustion calculations as well. Therefore, once the simulation of the reference GEP was finished, the resulting flow conditions at intake valve closing (IVC) were considered as initial conditions for simulating the combustion phase or closed cycle.

Boundary conditions have been obtained by simplified models and also with direct measurements. Solid walls of the cylinder liner, piston, head, intake-exhaust ports and valves were considered isothermal and their temperature was estimated by a lumped model [37]. The inflow and outflow boundaries located at the end of the intake-exhaust ports were fixed by the instantaneous pressure signals registered at the manifolds. Also, the temperature at these boundaries was assumed constant and equal to the mean value of the measurements at the same manifolds.

Finally, a point monitor located at the same position of the pressure transducer was used for recording the in-cylinder pressure evolution. This pressure signal was registered at a sampling frequency of $50 \mathrm{kHz}$, keeping the usable aliasingfree bandwidth within the human hearing range.

\subsection{Theoretical tools}

Apart from the CFD model, other numerical tools were used with the purpose of providing relevant combustion and noise metrics for the validation.

For example, the rate of heat release of the measurements was calculated from the in-cylinder pressure by means of the energy equation and some simplifications $[38,39]$. This equation was solved assuming uniform pressure and temperature throughout the whole combustion chamber volume, yielding the instantaneous mean temperature and the heat release. In the simulations, this metric was directly extracted from the combustion model outputs.

The maximum pressure rise rate was obtained by identifying the peaks of the $\mathrm{d} p / \mathrm{d} t$ signal with numerical algorithms and it was considered in angular units ( $\mathrm{MPa} / \mathrm{cad}$ ) because the engine speed was constant and equal to $1500 \mathrm{rpm}$ in all considered tests. This and the following metrics were calculated by applying the same procedure in the measurements and in the simulations.

The combustion efficiency was determined from both carbon monoxide (CO) and unburned hydrocarbons (HC) levels as

$$
\eta_{\text {comb }}=\left(1-\frac{m_{\mathrm{HC}}}{m_{\text {fuel }}}-\frac{m_{\mathrm{CO}}}{4.03 \cdot m_{\text {fuel }}}\right) \cdot 100
$$


where $m_{\mathrm{HC}}$ represents the mass of unburned HC emissions, $m_{\mathrm{CO}}$ is the mass of $\mathrm{CO}$ and $m_{\text {fuel }}$ is the injected mass fuel. The ratio of the indicated $\left(\eta_{\mathrm{i}}\right)$ and combustion efficiencies, traditionally known thermodynamic efficiency $\left(\eta_{\text {th }}\right)$, it was utilised to give an idea of the cycle performance.

The overall level of engine noise, from now on termed $\mathrm{ON}$, assesses the radiated noise by the engine structure. This acoustic response is highly non-linear and time dependent $[40,41]$ and it is extremely influenced by the engine block design [42]. Nonetheless, the acoustic path between the source and the observer is commonly approximated by a simple transfer function. For instance, Anderton [43] proposed an approach which assumes a linear behaviour between both points, resulting on a standard engine block attenuation curve. Even though this simplification does not allow for an accurate prediction of the radiated noise level, it is useful to perform comparative studies, and several combustion noise metrics are defined following this method.

$$
\mathrm{ON}(\mathrm{dB})=10 \cdot \log \frac{\mathrm{P}_{\mathrm{N}}^{2}}{\mathrm{p}_{0}^{2}}
$$

ON is defined by equation 4 , where $p_{0}$ is a reference sound pressure of $20 \mu \mathrm{Pa}$, which corresponds to the minimum human hearing threshold. In addition, $P_{N}$ is defined as

$$
P_{\mathrm{N}}=\frac{1}{N} \cdot \sum_{f=f_{1}}^{f_{\mathrm{N}}} P(f)
$$

where $N$ is the number of harmonics between $f_{1}$ and $f_{\mathrm{N}}$, and $P(f)$ represents the Fast Fourier Transform (FFT) of the engine radiated signal. This latter signal is obtained by subtracting the block attenuation curve from the in-cylinder pressure spectrum [44].

The CFD model was combined with the statistical technique DoE in order to optimise the injector configuration. According to the knowledge acquired during previous investigations [14, 18], the authors defined a reference configuration with three optimisation parameters. The test plan was based on a Central Composite Design (CCD) of three factors and it consist in 15 simulations. In addition, RSM was used to determine the relationships between the injector parameters configuration and the output variables mentioned above.

Figure 2 shows the reference configuration of the injector. The first set of orifices, recommended for early injections, have an included angle of $90^{\circ}\left(\alpha_{1}\right)$ and 12 orifices whereas the second one is suggested for late injections with an included angle of $148^{\circ}\left(\alpha_{2}\right)$ and 8 holes. Although this system could operate such a double-row nozzle injector with a single needle actuator [45], the target of this study is not to evaluate a solution which could improve the sprays overlap. The main idea aims at exclusively utilizing a particular set of nozzles in each injection event, allowing the independent use of two conventional configurations in subsequent injections. Thereby, the fuel was injected through the first set of orifices during the pilot and main injections whereas the second set was only used for the post injection.

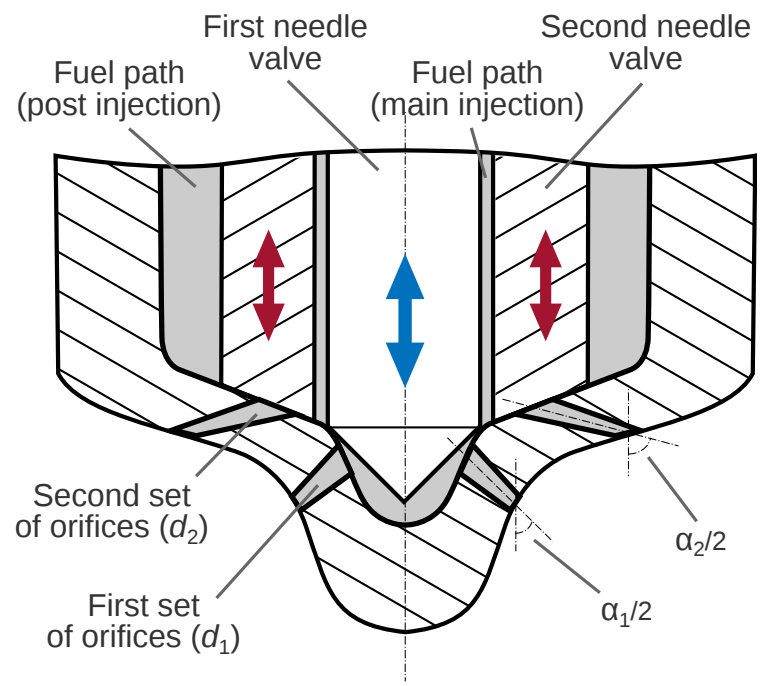

Figure 2: Injector sketch based on Perr's patent [19]. The injector actuators are completely independent and they are connected to a specific set of orifices.

The total injection areas of both crowns of orifices, $A_{1}$ and $\mathrm{A}_{2}$, were considered as optimization parameters. In both cases the number of orifices and the discharge coefficient for each hole remained fixed. Thus, the injection duration was adapted to maintain the injection pressure as well as the total injected mass between each configuration. The third optimization parameter was the split between the main and post injection masses $\left(\delta_{\text {main-post }}\right)$; the mass of the pilot injection was maintained constant since it was experimentally observed that its effects were less significant than those of the other injections. This parameter represents the amount of fuel mass added or removed from the main injection. Thus, the fuel mass of each injection was obtained by

$$
\begin{aligned}
& \operatorname{MoI}_{\text {main }}=\mathrm{m}_{\text {total }} \cdot\left(0.5+\frac{\delta_{\text {main-post }}}{100}\right) \\
& \mathrm{MoI}_{\text {post }}=\mathrm{m}_{\text {total }} \cdot\left(0.5-\frac{\delta_{\text {main-post }}}{100}\right)
\end{aligned}
$$

where $\mathrm{m}_{\text {total }}$ is the available fuel amount for both injections. Additional details about the factor space, input factors and specified ranges are displayed in Table 2.

\subsection{Validation}

The model was validated in depth in previous publications $[14,18]$. In these works the validation method compared the in-cylinder pressure at the same location as the pressure transducer in both time and frequency domains.

As an example, Figure 3 show the validation results of an operation condition defined by a medium speed (1500 rpm) and medium-high load (1.04 MPa of Indicated Mean Effective Pressure). Clearly, the model shows a good agreement with the measurements in both domains since the pressure prediction exhibits a deviation similar to measurements dispersion. Both research works have also shown the suitability 
Table 2: Values of the parameters used in each of the fifteen numerical simulations according to the test plan of the DoE study

\begin{tabular}{|c|c|c|c|c|c|c|c|}
\hline \multirow{2}{*}{$\begin{array}{c}\text { Factor } \\
\text { Parameter }\end{array}$} & \multicolumn{2}{|c|}{$1^{\mathrm{a}}$} & \multicolumn{2}{|c|}{$2^{\mathrm{b}}$} & \multicolumn{3}{|c|}{3} \\
\hline & $A_{1}[\%]$ & $d_{1}[\mu \mathrm{m}]$ & $A_{2}[\%]$ & $d_{2}[\mu \mathrm{m}]$ & $\delta_{\text {main-post }}[\%]$ & $\mathrm{MoI}_{\text {main }}[\mathrm{mg}]$ & $\mathrm{MoI}_{\text {post }}[\mathrm{mg}]$ \\
\hline 0 & 0.0 & 90.0 & 0.0 & 90.0 & 0.0 & 7.59 & 7.59 \\
\hline 1 & -17.8 & 81.6 & -17.8 & 81.6 & -11.9 & 5.78 & 9.39 \\
\hline 2 & -17.8 & 81.6 & 17.8 & 97.7 & -11.9 & 5.78 & 9.39 \\
\hline 3 & 17.8 & 97.7 & -17.8 & 81.6 & -11.9 & 5.78 & 9.39 \\
\hline 4 & 17.8 & 97.7 & 17.8 & 97.7 & -11.9 & 5.78 & 9.39 \\
\hline 5 & -17.8 & 81.6 & -17.8 & 81.6 & 11.9 & 9.39 & 5.78 \\
\hline 6 & -17.8 & 81.6 & 17.8 & 97.7 & 11.9 & 9.39 & 5.78 \\
\hline 7 & 17.8 & 97.7 & -17.8 & 81.6 & 11.9 & 9.39 & 5.78 \\
\hline 8 & 17.8 & 97.7 & 17.8 & 97.7 & 11.9 & 9.39 & 5.78 \\
\hline 9 & 0.0 & 90.0 & 0.0 & 90.0 & -20.0 & 4.55 & 10.62 \\
\hline 10 & 0.0 & 90.0 & 0.0 & 90.0 & 20.0 & 10.62 & 4.55 \\
\hline 11 & -30.0 & 75.3 & 0.0 & 90.0 & 0.0 & 7.59 & 7.59 \\
\hline 12 & 30.0 & 102.6 & 0.0 & 90.0 & 0.0 & 7.59 & 7.59 \\
\hline 13 & 0.0 & 90.0 & -30.0 & 75.3 & 0.0 & 7.59 & 7.59 \\
\hline 14 & 0.0 & 90.0 & 30.0 & 102.6 & 0.0 & 7.59 & 7.59 \\
\hline
\end{tabular}

${ }^{\mathrm{a}}$ Pilot and main injections

b Post injection

of the model to predict the in-cylinder pressure field in different operation settings [18] or even operating with other combustion concepts, such as CDC [14].

Special attention was paid in the high frequency content where the mesh size and the time step are determinant to ensure an accurate estimation [46]. During the first stages of this research, the authors observed that both parameters strongly condition the amplitude of resonant pressure oscillations. In this way, a cell size of $0.75 \mathrm{~mm}$ guarantees enough spatial resolution to reproduce the standing waves generated during the combustion. Furthermore, they determined that only one cell must be swept by a pressure wave between two consecutive time steps of the calculation $\left(\mathrm{C}_{\mathrm{c}} \simeq 1\right)$, otherwise pressure oscillations are rapidly attenuated.

\section{Results and discussion}

In this section, data resulting from the study is presented and discussed. First, noise emissions are compared with other relevant engine outputs so as to identify general trends and the optimum configuration. Then, the optimum configuration found by the DoE method will be compared against the baseline configuration.

\subsection{DoE results}

Following guidelines defined by the RSM method, all variables obtained at each point of the DoE space were interpolated using a cubic polynomial fit for visualization. Results are plotted in Fig. 4 in which the computed contours of overall noise and indicated efficiency $\left(\eta_{\mathrm{i}}\right)$ are presented with the purpose of analyzing the tendencies followed by both parameters.
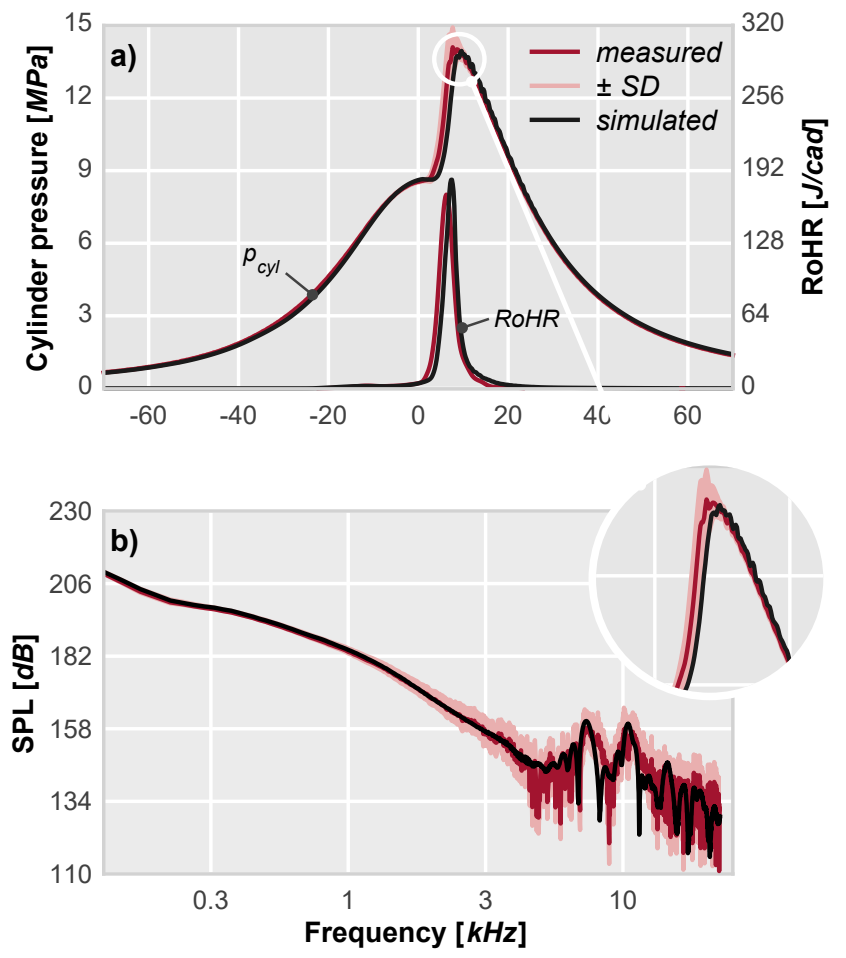

Figure 3: Experimental validation of the numerical model in terms of in-cylinder pressure and rate of heat release (a) and frequency content in sound pressure level (SPL) of the pressure signal (b). The standard deviation $(S D)$ is included in order to compare the solution with the measurement dispersion due to cycle-to-cycle variations 
It can be seen how the split between main and post injections is the most dominant parameter among those selected in the study. While the maximum change of $\delta_{\text {main-post }}$ modifies the overall noise in almost $14 \mathrm{~dB}, \mathrm{~A}_{1}$ and $\mathrm{A}_{2}$ parameters only produce a variation of $8 \mathrm{~dB}$. In a similar way, the indicated efficiency varies 4.5 and 2 points, respectively. Also, contour distributions presented by both parameters, $\mathrm{ON}$ and $\eta_{\mathrm{i}}$, are practically the same in the three considered planes. This behavior evinces the trade-off trend observed by other authors $[16,14]$ and it shows the close relationship between these parameters.

Focusing on the first plane, the evolution of combustion noise and indicated efficiency is plotted against the variation of $A_{1}$ and $A_{2}$. Both parameters decrease in the bottom-right hand side region, in which the total injection area of the first crown is excessively increased. On the other hand, the higher levels are achieved by reducing the diameter of both sets of orifices.

Examination of the second and the third planes reveals that $\mathrm{ON}$ and $\eta_{\mathrm{i}}$ increase significantly as the quantity of fuel in the main injection rises. Besides, a configuration with small orifices in the first crown and with big orifices in the second one offers the highest levels of efficiency.

In all these cases, both parameters show a monotonic trend, and thus only a compromise solution between performance and noise emissions seems to be achievable.

Nonetheless, a further examination of the complete DoE space show that these trends change for certain configurations, allowing to improve the compromise solution of this particular system design. In particular, this behavior can be clearly observed in the plane plotted in Fig. 5. This corresponds with a fixed split injection of $-11.9 \%$ and different values of $A_{1}$ and $A_{2}$. While the bottom-left hand side of the map show the lowest noise values, the region which maximizes the efficiency is located in the middle-right hand side.

In order to identify the optimum configuration within the whole DoE space, a merit function based on two parameters [47] was defined as

$$
\begin{array}{r}
\left.\mathrm{MF}=\frac{1000 \cdot \sum_{\mathrm{n}=1}^{2} \alpha_{\mathrm{n}}}{\sum_{\mathrm{n}=1}^{2}\left(\alpha_{\mathrm{n}} \cdot \mathrm{e}^{\beta_{\mathrm{n}} \cdot \frac{x_{\mathrm{n}}-x_{\mathrm{n}}^{\text {target }}}{x_{\mathrm{n}}^{\text {target }}}}\right)}\right) \\
x_{1} \longrightarrow \mathrm{ON} \quad x_{2} \longrightarrow \eta_{\mathrm{i}}
\end{array}
$$

where $x_{\mathrm{n}}$ is the value of each parameter at a given configuration (ON and $\eta_{\mathrm{i}}$ ), $x_{\mathrm{n}}^{\text {target }}$ stands for these values achieved by the original configuration and both $\alpha_{\mathrm{n}}$ and $\beta_{\mathrm{n}}$ are weighted constants for specifying the influence of each parameter in the merit function. For this particular study, the constants where fixed at 10 for $\mathrm{ON}$ parameter and at 8 for the indicated efficiency, giving more relevance to the combustion noise. This decision was made taking into account the extremely high levels of noise registered in this combustion concept. Merit function values at each considered configuration are presented in Fig. 6 in which the optimum configuration can
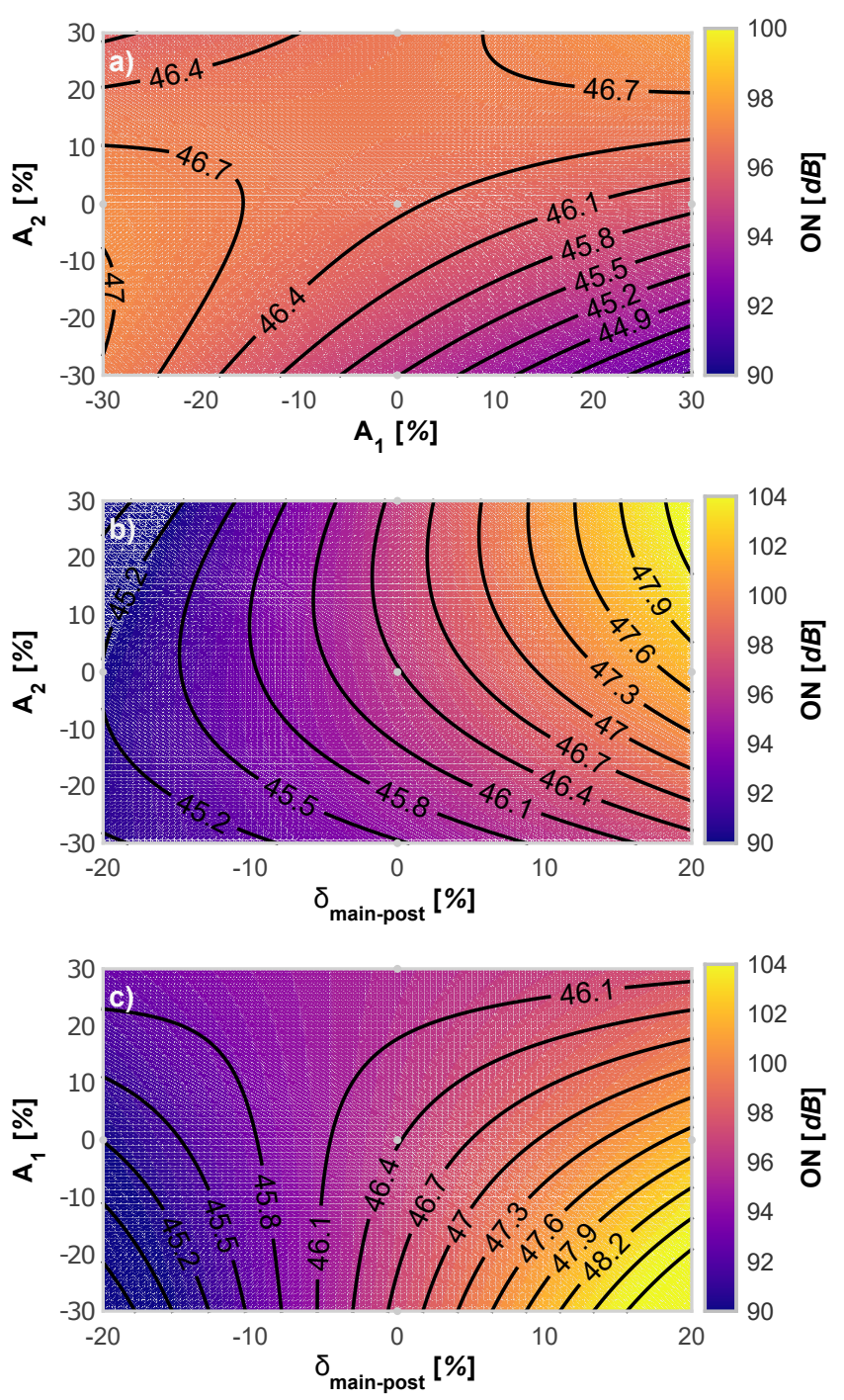

Figure 4: Results of DoE interpolation procedure, overall noise and indicated efficiency contours are superposed along the three main DoE space planes. a) Plane 0-11-12-13-14, b) Plane 0-9-10-13-14 and c) Plane 0-9-10-11-12.

be identified. This configuration is therefore formed by two crowns with the same diameter of nozzle holes $(90 \mu \mathrm{m})$ and an injection split clearly displaced to the post injection event (30-70\%).

In addition to the merit function, $\mathrm{NO}_{\mathrm{x}}$ levels were restricted to the baseline configuration. In Fig. 6 those cases which do not comply with this constraint are identified in grey. All these configurations have a fuel mass split clearly displaced to the main injection (see Table 2), thereby evincing that $\mathrm{NO}_{\mathrm{x}}$ levels increase when the main becomes larger than the post injection.

\subsection{Optimized vs. baseline comparison}

Once the optimum double crown configuration is identified, a direct comparison against the baseline can be performed for determining the most influential parameters and 
Table 3: Comparison of the estimated metrics related to the engine performance and emissions.

\begin{tabular}{lcc}
\hline Configuration & $\begin{array}{c}\text { Original } \\
\text { (baseline) }\end{array}$ & $\begin{array}{c}\text { Optimum } \\
\text { (double crown) }\end{array}$ \\
\hline Overall noise [dB] & 99.7 & 91.0 \\
Indicated eff. [\%] & 46.9 & 45.0 \\
Combustion eff. [\%] & 96.5 & 98.0 \\
Thermodynamic eff. [\%] & 48.6 & 45.9 \\
$\mathrm{NO}_{\mathrm{x}}$ [mg/s] & 0.60 & 0.31 \\
\hline
\end{tabular}

their impact on the combustion. In a first step, five relevant parameters were selected and also included in Table 3. A noticeable reduction of the overall noise level is observed, going from 99.7 to $91.0 \mathrm{~dB}$. Improvements in $\mathrm{NO}_{\mathrm{x}}$ levels are even more remarkable, since these decrease from $0.60 \mathrm{mg} / \mathrm{s}$ to $0.31 \mathrm{mg} / \mathrm{s}$ (almost a $50 \%$ reduction).

However, despite the benefits of reducing both noise and $\mathrm{NO}_{\mathrm{x}}$ emissions, a significant efficiency worsening is provoked. Table 3 shows a non-negligible reduction of 1.9 percentage points in the indicated efficiency levels.

In a previous work [14], the research group showed how the identification of the losses origin can provide additional insight on this regard. They also displayed the propensity of PPC gasoline combustion to generate high levels of CO and unburned HC as the combustion stability is deteriorated, worsening the combustion efficiency and subsequently, decreasing the thermal efficiency.

As it can be seen in the same Table 3, these trends are not replicated by the new configuration. While the indicated efficiency is conditioned by the combustion stability in the baseline, it is hardly influenced by thermodynamic losses in the optimum case.

In order to understand why efficiency trends change when the injection system is modified, the evolution of the liquid film impegnement at cylinder and piston surfaces is plotted in Fig. 7. Moreover, a visualization of the sprays at both pilot and main injection phases is provided in this figure. The

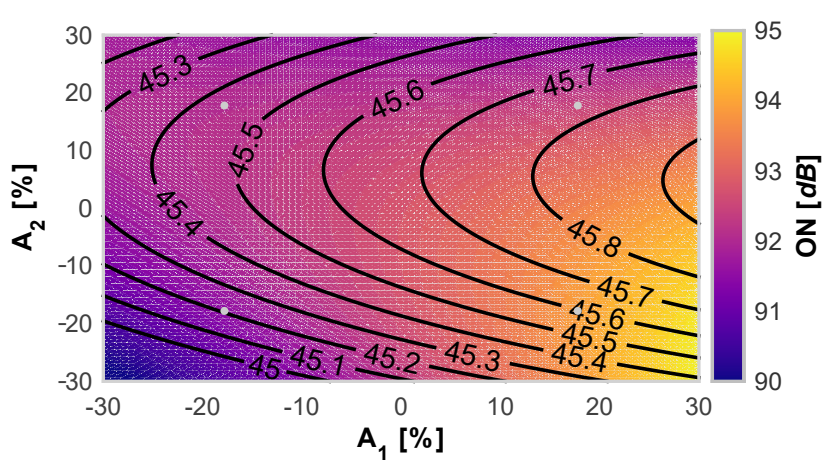

Figure 5: Results of DoE interpolation procedure in terms of overall noise and indicated efficiency across the plane 1-2-34.

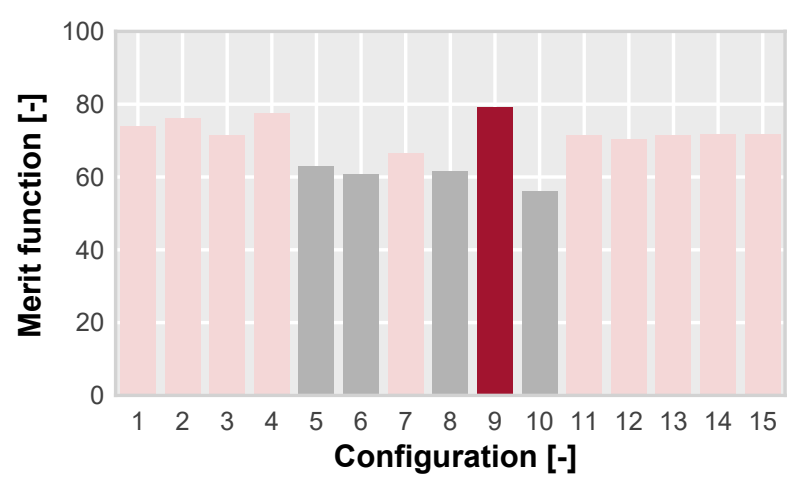

Figure 6: Results of the selection procedure for choosing an optimum configuration. The optimum case (9) is distinguished in red while configurations that do not comply with the $N O_{x}$ constraint are identified in grey.

\section{Original (baseline)}
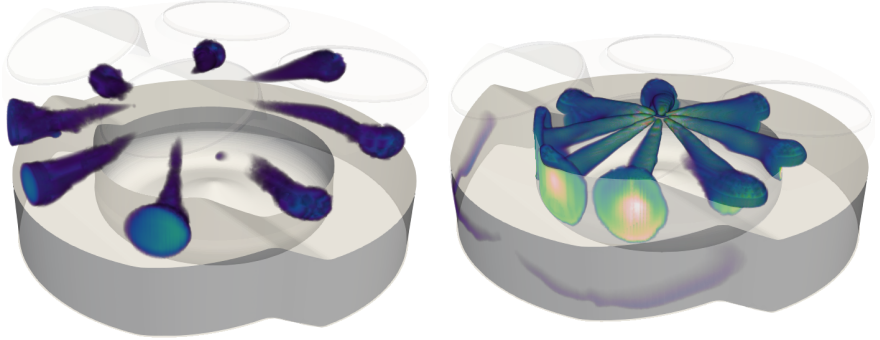

Optimum (double crown)

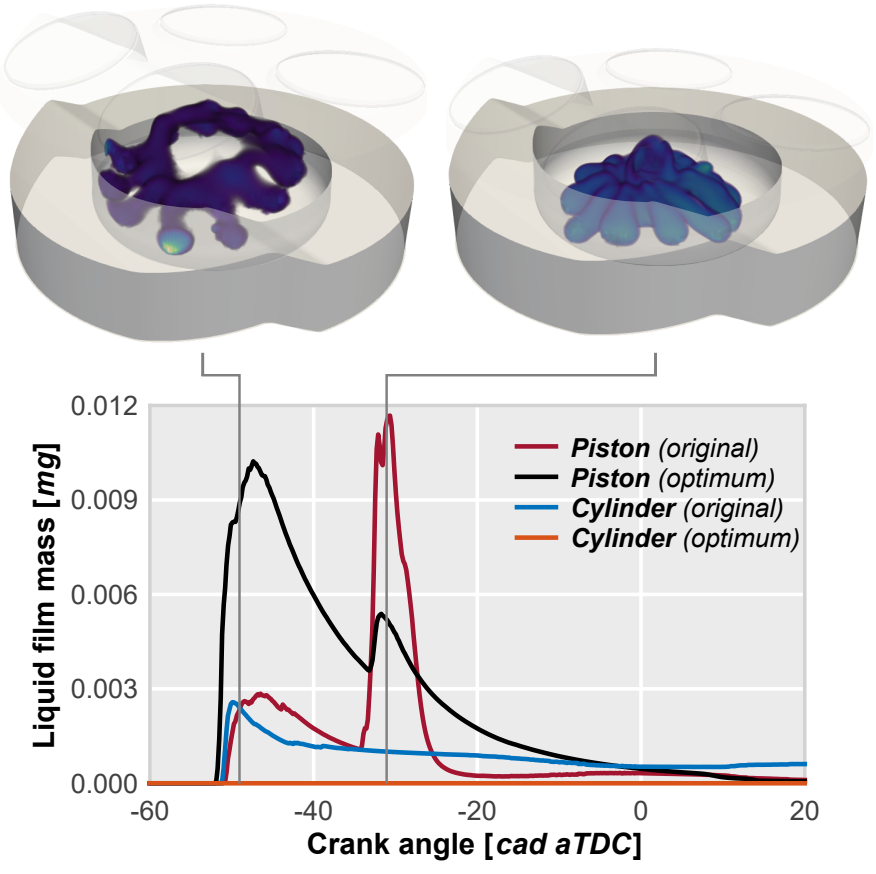

Figure 7: Time evolution of the liquid film impingement at cylinder walls and piston surface in both considered injector configurations (bottom). Visualization of baseline and optimized sprays at two different instants during the pilot and main injections (top).

sprays are visualized in this figure by clipping the equivalence ratio $(\phi)$ at the unitary value, thereby showing the isovolume of stoichiometric conditions enclosing the spray. 
Examination of the figure reveals that the baseline configuration tends to generate fuel liquid deposits at cylinder walls and squish regions. These fuel deposits, which are the main cause of the oil dilution, are maintained until the end of the closed cycle, increasing the unburned HC levels at the exhaust. The optimum configuration instead avoids these issues by leading the fuel into the piston bowl.

Despite the gain in terms of combustion stability, losses due to the thermodynamic effects are so large that compromise thermal efficiency levels in a significant way. Thus, incylinder pressures of the two considered configurations are plotted together with the RoHR traces in Fig. 8 in order to identify the source of these losses. As can be seen, the combustion phasing is excessively displaced towards the expansion stroke if the optimum configuration is compared to the baseline. This fact allows to recognize the combustion phasing as a possible shortcoming of this new system configuration, at least with the considered injection settings.

In addition to this fundamental analysis, it is important to understand how the fuel stratification modifies the reactivity of the charge. Hence, the RoHR was numerically integrated along the whole CFD domain with respect to the equivalence ratio $(\phi)$ in order to analyze the fuel stratification and its temporal evolution during the combustion. The solutions are presented in Fig. 9 in which the horizontal axis
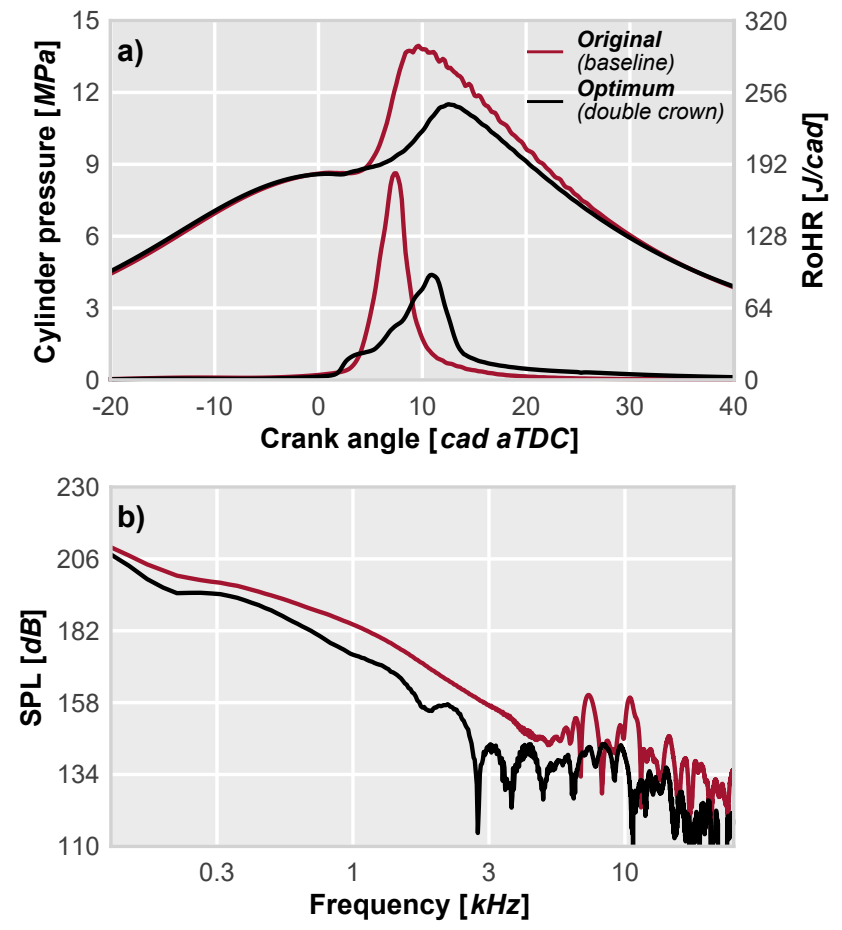

Figure 8: Comparison between original (baseline) and optimum (double crown) injector configurations. Differences in terms of cylinder pressure (obtained at the transducer location) and rate of heat release are plotted in a) whereas pressure spectra are presented in $b$ ).
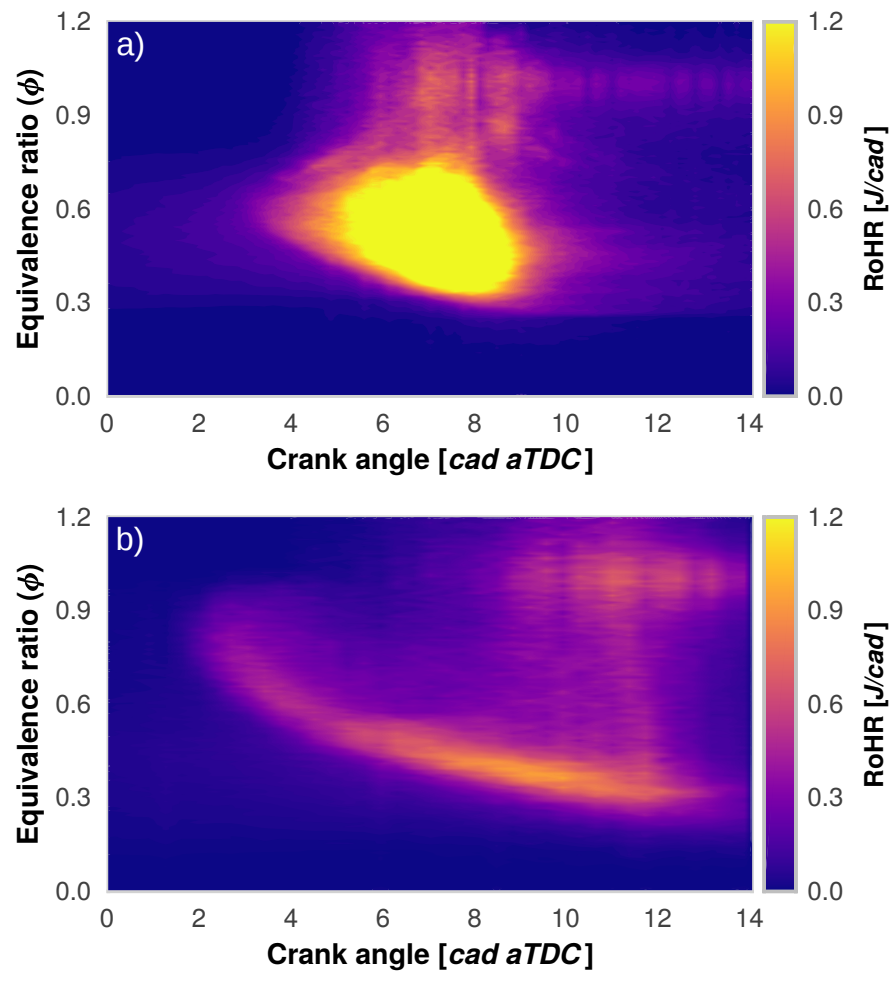

Figure 9: Comparison of the fuel stratification. RoHR contours along the equivalence ratio $(\phi)$ and crank angle degree are plotted for the baseline in a) and for the optimum in $b$ ).

represents the temporal evolution of the engine cycle, the vertical axis shows the integration variable $(\phi)$ and the color scale displays the RoHR.

It can be seen in this figure that the most reactive blend in the baseline case is focused on the middle range of equivalence ratios $(0.35-0.7)$, causing a single-step combustion with high burning rates. In the optimum configuration however, the blend shows a higher level of stratification with mixtures gathered by 0.3 and 1.2 of equivalence ratios. Here, the combustion starts at near stoichiometric conditions $(0.8-$ 1.0), then it progresses toward lower equivalence ratios $(0.5$ $-0.3)$ and finally, it consumes the richest mixtures $(1.0-1.2)$ within the chamber. This singular path leads to a progressive burn that results in a smoother combustion law.

From the in-cylinder pressure side, lower burning rates mean lower pressure rise rates. Consequently, the overall amplitude of the in-cylinder pressure spectrum is remarkably decreased in the whole broadband (see Fig. 8b).

The noise lowering associated to this effect is a straight consequence of two documented mechanisms. On one hand, the relaxation of the pressure rise rate produces a reduction of the SPL in the frequencies contained between 0.2 and 3.0 $\mathrm{kHz}[48,49]$. On the other hand, the contribution of the combustion chamber resonance is also reduced as the amplitude of high frequency oscillation modes $(>3.0 \mathrm{kHz})$ is notably decreased $[50,51]$. Low frequencies $(<0.2 \mathrm{kHz})$ were excluded 
from the comparison since they mainly depend on the engine speed [52] that, in this case, was kept constant among both configurations.

\subsection{Sensitivity of the injection settings}

With the aim of exploring the margin of improvement and the sensitivity of the new system configuration, an additional study was performed by sweeping $\mathrm{SoE}_{\text {main }}$ each 6 cad between -52 and -34 cad aTDC in both configurations. This injection parameter was specifically selected for its notable impact on the combustion phasing [22].

The interest of the analysis is focused on examining the emissions and performance parameters used before. Results, presented in Fig. 10, show the influence of varying SoE $_{\text {main }}$ in the original and the optimum combustion systems.

Focusing on the baseline, a trade-off is evident between emissions (noise and $\mathrm{NO}_{\mathrm{x}}$ ) and efficiency. This was reported using direct engine measurements, and also supported by numerical simulations [16, 14] for providing a better understanding of the mixture stratification and the pollutants formation. Moreover, a more recent publication [12] shows how the main cause of these efficiency losses is the deterioration of the combustion stability due to an excessive fuel wall impingement.

Regarding the double crown configuration, Fig. 10 shows how it is less sensitive to $\mathrm{SoE}_{\text {main }}$ since all studied parameters present a lower maximum variation. For instance, while noise levels vary $5.7 \mathrm{~dB}$ for the new configuration, the baseline exhibit $16.6 \mathrm{~dB}$ of maximum difference. In addition, the proposed system is able to keep the combustion efficiency above the baseline even for extremely advanced $\mathrm{SoE}_{\text {main }}$.

Thanks to this, the indicated efficiency is preserved at acceptable values despite the modest values of thermodynamic efficiency. Therefore, the improvement of the combustion stability seems to be the greatest improvement of the proposed configuration, making the new system potentially advantageous.

Finally, trends are reversed with respect to the baseline since, as it can be seen, both emissions and efficiency increase as SoE $_{\text {main }}$ is advanced. Thus, a delay on the main injection timing improves the indicated efficiency whereas noise and $\mathrm{NO}_{\mathrm{x}}$ emissions are kept at the lowest level.

\section{Conclusions}

In view of the challenges to manage combustion noise of partially premixed gasoline combustion in compressionignited engines, this paper evaluates the potential of using dual spray injectors in a 2-stroke engine with a combination of numerical simulations and statistical design of experiments. With this, it has been possible to perform a qualitative analysis of the relationships between several injector design parameters and their engine outputs, thereby contributing to the understanding of the combustion noise control in this singular combustion concept.
The robustness of the methodology has been demonstrated by the results of the validation which takes into account not only the classical engine outputs but also the most relevant noise metrics.

Results from DoE have revealed that the proposed configuration allows to decrease both noise and $\mathrm{NO}_{\mathrm{x}}$ emissions while efficiency values decreases due to an excessively delayed combustion timing. The new configuration is composed by two crowns with the same diameter of nozzle holes and an injection split clearly displaced to the post injection event. This helps to control the reactivity of the mixture and permitting a smoother combustion law which reduces the noise of the combustion in the whole broadband.

In addition to noise and $\mathrm{NO}_{\mathrm{x}}$ emissions lowering, this new configuration present a less sensitive response to the injection timing, improving the combustion stability but declining the control of the combustion phasing. However, the considerable higher levels of combustion efficiency allow to maintain the performance at competitive values even with the poor achieved values of thermodynamic efficiency.

Finally, the presented statistical methodology has allowed a better understanding of the benefits that a new technological solution can bring in order to reduce combustion noise, and at the same time to determine possible drawbacks which might compromise its potential application.

Further analysis is nonetheless needed for a more complete optimization of the new system, including additional design parameters that in this study were considered fixed. Moreover, further efforts should be applied to the numerical results post-processing for providing more insight about the combustion process and its related noise generation mechanisms.

\section{Acknowledgements}

The equipment used in this work has been partially supported by FEDER project funds "Dotación de infraestructuras científico técnicas para el Centro Integral de Mejora Energética y Medioambiental de Sistemas de Transporte (CiMeT), (FEDERICTS-2012-06)" from the operational program of unique scientific and technical infrastructure of the Spanish Ministerio de Economía y Competitividad.

J. Gomez-Soriano is partially supported by an FPI contract (FPI-S2-2016-1353) of the "Programa de Apoyo para la Investigación y Desarrollo (PAID-01-16)" of the Universitat Politècnica de València.

The authors want to express their gratitude to CONVERGENT SCIENCE Inc. and Convergent Science GmbH for their kind support for the CFD calculations with the CONVERGE software.

\section{References}

[1] M. Kampa, E. Castanas, Human health effects of air pollution, Environmental Pollution 151 (2) (2008) 362 - 367, proceedings of the 4th International Workshop on Biomonitoring of Atmospheric Pollution (With Emphasis on Trace Elements). doi:10.1016/j.envpol. 2007.06.012. 

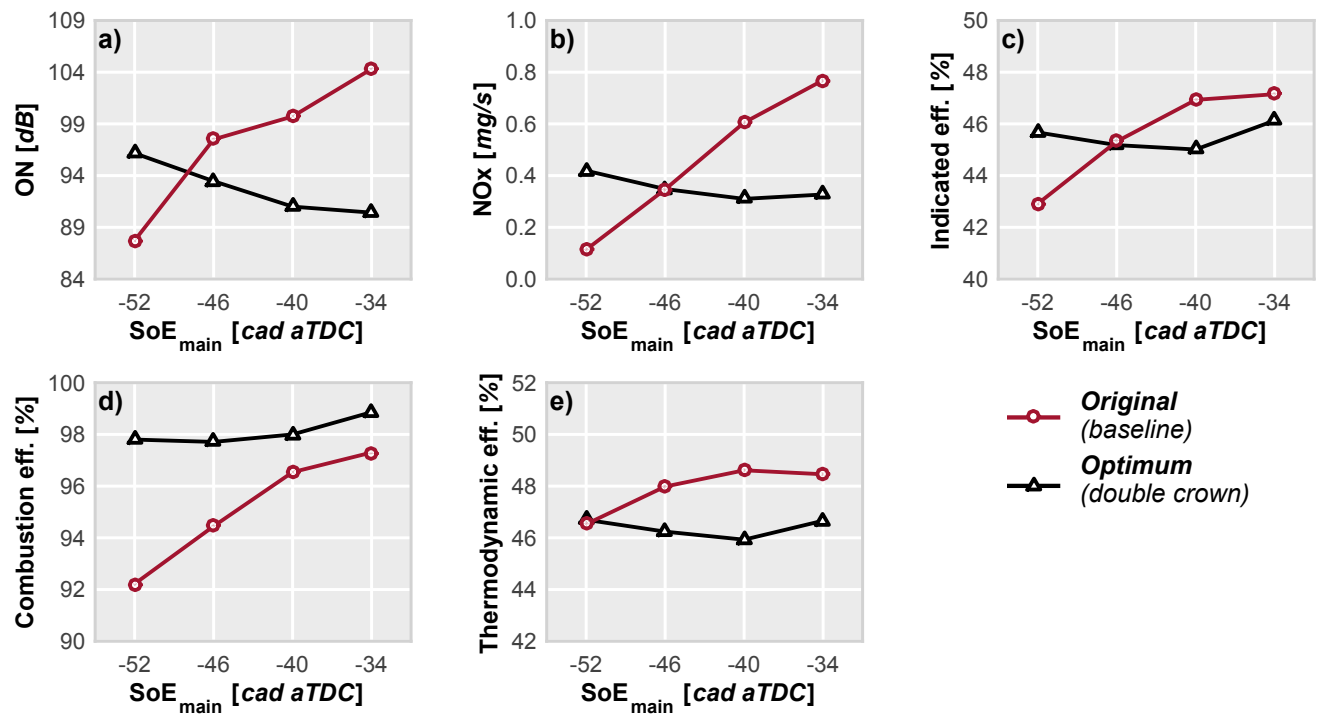

Figure 10: Influence of $S o E_{\text {main }}$ on emissions (noise and $N O_{X}$ ) and engine performance (indicated, combustion and thermodynamic efficiencies) in the baseline and the optimum configurations.

[2] The Sustainable Development Goals Report 2016, Tech. rep., DESA (2016). doi:http://dx.doi.org/10.18356/3405d09f-en.

[3] M. Guarnieri, Looking back to electric cars, in: 2012 Third IEEE HISTory of ELectro-technology CONference (HISTELCON), 2012, pp. 1-6. doi: 10.1109/HISTELCON. 2012.6487583.

[4] R. Hanson, D. Splitter, R. Reitz, Operating a heavy-duty directinjection compression-ignition engine with gasoline for low emissions, in: SAE Technical Paper, Vol. 2009-01-1442. doi:10.4271/ 2009- 01 - 1442.

[5] V. Manente, B. Johansson, P. Tunestal, W. Cannella, Effects of different type of gasoline fuels on heavy duty partially premixed combustion, SAE International Journal of Engines 2 (2) (2010) 71-88. doi:10. 4271/2009- $01-2668$.

[6] J. Benajes, R. Novella, D. De Lima, P. Tribotte, N. Quechon, P. Obernesser, V. Dugue, Analysis of the combustion process, pollutant emissions and efficiency of an innovative 2-stroke HSDI engine designed for automotive applications, Applied Thermal Engineering 58 (2013) 181-193. doi:10.1016/j . applthermaleng . 2013.03.050.

[7] O. Laget, C. Ternel, J. Thiriot, S. Charmasson, P. Tribotté, F. Vidal, Preliminary design of a two-stroke uniflow diesel engine for passenger car, in: SAE Technical Paper, Vol. 2013-01-1719. doi:10.4271/ 2013-01- 1719.

[8] A. J. Torregrosa, A. Broatch, R. Novella, L. F. Mónico, Suitability analysis of advanced diesel combustion concepts for emissions and noise control, Energy 36 (2) (2011) 825-838. doi:10.1016/j.energy. 2010.12.032.

[9] A. Torregrosa, A. Broatch, R. Novella, J. Gomez-Soriano, L. Mónico, Impact of gasoline and diesel blends on combustion noise and pollutant emissions in premixed charge compression ignition engines, Energy 193 (2017) 515-530. doi:10.1016/j . energy.2017.07.010.

[10] A. Vressner, A. Lundin, M. Christensen, P. Tunestål, B. Johansson, Pressure Oscillations During Rapid HCCI Combustion, SAE Technical Paper 2003-01-3217. doi:10.4271/2003-01-3217.

[11] R. Hickling, D. A. Feldmaier, S. H. Sung, Knock-induced cavity resonances in open chamber Diesel engines, The Journal of the Acoustical Society of America 65 (5) (1979) 1474-1479. doi:10.1121/1. 382910.

[12] J. Benajes, R. Novella, D. D. Lima, K. Thein, Impact of injection settings operating with the gasoline partially premixed combustion concept in a 2-stroke HSDI compression ignition engine, Applied Energy 193 (2017) 515 - 530. doi:10.1016/j . apenergy . 2017.02 .044.
[13] J. Benajes, A. García, J. M. Pastor, J. Monsalve-Serrano, Effects of piston bowl geometry on reactivity controlled compression ignition heat transfer and combustion losses at different engine loads, Energy 98 (2016) 64 - 77. doi:10.1016/j . energy.2016.01.014.

[14] A. Broatch, X. Margot, R. Novella, J. Gomez-Soriano, Combustion noise analysis of partially premixed combustion concept using gasoline fuel in a 2-stroke engine, Energy 107 (2016) 612 - 624. doi: $10.1016 / j$. energy . 2016.04.045.

[15] J. Benajes, J. Martín, R. Novella, K. Thein, Understanding the performance of the multiple injection gasoline partially premixed combustion concept implemented in a 2-stroke high speed direct injection compression ignition engine, Applied Energy 161 (2016) 465 - 475. doi: 10.1016/j . apenergy . 2015.10.034.

[16] J. Benajes, R. Novella, D. De Lima, P. Tribotte, Investigation on multiple injection strategies for gasoline PPC operation in a newly designed 2stroke HSDI compression ignition engine, Vol. 8, 2015, pp. 758-774. doi : 10.4271/2015-01-0830.

[17] B. Yang, L. Wang, L. Ning, K. Zeng, Effects of pilot injection timing on the combustion noise and particle emissions of a diesel/natural gas dual-fuel engine at low load, Applied Thermal Engineering 102 (2016) 822 - 828. doi: 10.1016/j . appl thermaleng. 2016.03.126.

[18] A. Broatch, X. Margot, R. Novella, J. Gomez-Soriano, Impact of the injector design on the combustion noise of gasoline partially premixed combustion in a 2-stroke engine, Applied Thermal Engineering 119 (2017) 530 - 540. doi:10.1016/j . applthermaleng . 2017 .03.081.

[19] J. Perr, J. Perr, L. Peters, D. Benson, J. Carroll, Variable spray hole fuel injector with dual actuators, US Patent 6,557,779. URL https://Www. google.ch/patents/US6557779

[20] J. Benajes, R. Novella, J. M. Pastor, A. Hernández-López, M. Hasegawa, N. Tsuji, M. Emi, I. Uehara, J. Martorell, M. Alonso, Optimization of the combustion system of a medium duty direct injection diesel engine by combining $\{$ CFD $\}$ modeling with experimental validation, Energy Conversion and Management 110 (2016) 212 - 229. doi:10.1016/ j. enconman. 2015.12.010.

[21] A. López, J. Aisa, A. Martinez, D. Mercado, Injection moulding parameters influence on weight quality of complex parts by means of \{DOE\} application: Case study, Measurement 90 (2016) 349 - 356. doi: https:10.1016/j . measurement. 2016.04.072.

[22] J. Benajes, R. Novella, D. De Lima, P. Tribotté, Analysis of combustion concepts in a newly designed two-stroke high-speed direct injection compression ignition engine, International Journal of Engine Researchdoi: 10.1177/1468087414562867. 
[23] P. Tribotte, F. Ravet, V. Dugue, P. Obernesser, N. Quechon, J. Benajes, R. Novella, D. De Lima, Two strokes diesel engine - promising solution to reduce $\mathrm{CO} 2$ emissions, Procedia - Social and Behavioral Sciences 48 (2012) 2295-2314. doi : 10.1016/j . sbspro.2012.06.1202.

[24] R. Christian, F. Knopf, A. Jaschek, W. Schindler, Eine neue messmethodik der bosch-zahl mit erhoehter empfindlichkeitl, Motortechnische Zeitschrift 54 (1993) 16-22.

[25] F. Ihlenburg, The medium-frequency range in computational acoustics: Practical and numerical aspects, Journal of Computational Acoustics 11 (02) (2003) 175-193. doi: 10.1142/S0218396X03001900.

[26] CONVERGENT SCIENCE Inc., CONVERGE 2.2 Theory Manual (2015).

[27] V. Yakhot, S. Orszag, Renormalization group analysis of turbulence. Journal of Scientific Computing 1 (1) (1986) 3-51. doi:10.1007/ BF01061452.

[28] C. Angelberger, T. Poinsot, B. Delhay, Improving near-wall combustion and wall heat transfer modeling in si engine computations, in: SAE Technical Paper, SAE International, 1997. doi : 10.4271/972881.

[29] A. J. Torregrosa, A. Broatch, X. Margot, J. Gomez-Soriano, Towards a Predictive CFD Approach for Assessing Noise in Diesel Compression Ignition Engines. Impact of the Combustion Strategies, International Conference on Modeling and Diagnostics for Advanced Engine systems: the 9th COMODIA, Okayama (Japan).

[30] A. Broatch, R. Novella, J. Gomez-Soriano, P. Pal, S. Som, Numerical Methodology for Optimization of Compression-Ignited Engines Considering Combustion Noise Control, SAE Technical Paper 2018-010193. doi: 10.4271/2018-01-0193.

[31] J. K. Dukowicz, A particle-fluid numerical model for liquid sprays, Journal of Computational Physics 35 (2) (1980) 229 - 253. doi: 10. 1016/0021-9991(80)90087-X.

[32] R. D. Reitz, J. C. Beale, Modeling spray atomization with the kelvinhelmholtz/rayleigh-taylor hybrid model, Atomization and Sprays 9 (6) (1999) 623-650.

[33] R. Payri, F. J. Salvador, J. Gimeno, G. Bracho, A new methodology for correcting the signal cumulative phenomenon on injection rate measurements, Experimental Techniques 32 (1) (2008) 46-49. doi: 10.1111/j.1747-1567.2007.00188.x

[34] P. K. Senecal, E. Pomraning, K. J. Richards, T. E. Briggs, C. Y. Choi, R. M. McDavid, M. A. Patterson, Multi-dimensional modeling of directinjection diesel spray liquid length and flame lift-off length using CFD and parallel detailed chemistry, in: SAE Technical Paper, SAE International, 2003. doi : 10.4271/2003-01- 1043.

[35] J. Brakora, R. D. Reitz, A comprehensive combustion model for biodiesel-fueled engine simulations, in: SAE Technical Paper, SAE International, 2013. doi: 10.4271/2013-01-1099.

[36] H. Hiroyasu, T. Kadota, Models for combustion and formation of nitric oxide and soot in direct injection diesel engines, in: SAE Technical Paper, SAE International, 1976. doi : 10.4271/760129.

[37] A. Torregrosa, P. Olmeda, B. Degraeuwe, M. Reyes, A concise wall temperature model for DI diesel engines, Applied Thermal Engineering 26 (11-12) (2006) 1320-1327. doi:10.1016/j.applthermaleng . $2005.10,021$.

[38] M. Lapuerta, O. Armas, J. J. Hernández, Diagnosis of DI diesel combustion from in-cylinder pressure signal by estimation of mean thermodynamic properties of the gas, Applied Thermal Engineering 19 (5) (1999) 513-529. doi : 10.1016/S1359-4311(98)00075- 1.

[39] F. Payri, S. Molina, J. Martín, O. Armas, Influence of measurement errors and estimated parameters on combustion diagnosis, Applied Thermal Engineering 26 (2-3) (2006) 226-236. doi:10.1016/j. applthermaleng . 2005.05.006.

[40] L. Stanković, J. F. Böhme, Time-frequency analysis of multiple resonances in combustion engine signals, Signal Processing 79 (1) (1999) 15-28. doi : 10 . 1016/S0165 - 1684 (99) 00077 - 8.

[41] J. M. Desantes, A. J. Torregrosa, A. Broatch, Wavelet transform applied to combustion noise analysis in high-speed DI Diesel engines, SAE Technical Paper 2001-01-1545. doi : 10 . 4271/2001-01-1545.

[42] O. Singh, T. Sreenivasulu, M. Kannan, The effect of rubber dampers on engine's NVH and thermal performance, Applied Acoustics 75 (2014) 17 - 26. doi : 10.1016/j . apacoust . 2013.07.007.

[43] D. Anderton, Relation between combustion system and engine noise, Vol. 790270, 1979. doi : 10.4271/790270.
[44] A. E. W. Austen, T. Priede, Origins of Diesel engine noise, in: SAE Technical Paper, SAE International, 1959. doi : 10.4271/590127.

[45] S. Choi, S.-H. Shin, J. Lee, K. Min, H. Choi, The effects of the combustion chamber geometry and a double-row nozzle on the diesel engine emissions, Proceedings of the Institution of Mechanical Engineers, Part D: Journal of Automobile Engineering 229 (5) (2015) 590-598. doi : 10.1177/0954407014547748.

[46] A. J. Torregrosa, A. Broatch, J. García-Tíscar, J. Gomez-Soriano, Modal decomposition of the unsteady flow field in compression-ignited combustion chambers, Combustion and Flame 188 (2018) 469-482. doi: 10. 1016/j . combustflame. 2017.10.007.

[47] S. Molina, C. Guardiola, J. Martín, D. García-Sarmiento, Development of a control-oriented model to optimise fuel consumption and no $\mathrm{x}$ emissions in a di diesel engine, Applied Energy 119 (2014) 405-416. doi: 10.1016/j . apenergy.2014.01.021.

[48] T. Priede, E. C. Grover, Paper 2: Noise of Industrial Diesel Engines, Proceedings of the Institution of Mechanical Engineers, Conference Proceedings 181 (3) (1966) 73-89. doi:10.1243/pime_conf_1966_ 181_062_02.

[49] F. Payri, A. Broatch, B. Tormos, V. Marant, New methodology for in-cylinder pressure analysis in direct injection diesel engines-application to combustion noise, Measurement Science and Technology 16 (2) (2005) 540-547. doi:10.1088/0957-0233/16/ 2/029.

[50] T. Priede, Relation between form of cylinder-pressure diagram and noise in diesel engines, Proceedings of the Institution of Mechanical Engineers: Automobile Division 14 (1) (1960) 63-97. doi: 10.1243/pime_auto_1960_000_012_02.

[51] A. J. Torregrosa, A. Broatch, X. Margot, V. Marant, Combustion chamber resonances in direct injection automotive Diesel engines: a numerical approach, International Journal of Engine Research 5 (1) (2003) 83-91. doi : 10. 1243/146808704772914264.

[52] A. J. Torregrosa, A. Broatch, J. Martín, L. Monelletta, Combustion noise level assessment in direct injection diesel engines by means of incylinder pressure components, Measurement Science and Technology 18 (7) (2007) 2131-2142. doi : 10 . 1088/0957 - 0233/18/7/045.

\section{List of Figures}

$1 \quad$ Computational domain and mesh characterization of the engine architecture at different calculation phases. . . . . . . . . .

2 Injector sketch based on Perr's patent [19]. The injector actuators are completely independent and they are connected to a specific set of orifices. . . . . . . . . . . . . . . .

3 Experimental validation of the numerical model in terms of in-cylinder pressure and rate of heat release (a) and frequency content in sound pressure level (SPL) of the pressure signal (b). The standard deviation (SD) is included in order to compare the solution with the measurement dispersion due to cycle-to-cycle variations

4 Results of DoE interpolation procedure, overall noise and indicated efficiency contours are superposed along the three main DoE space planes. a) Plane 0-11-12-13-14, b) Plane 0-910-13-14 and c) Plane 0-9-10-11-12. . . . . . .

5 Results of DoE interpolation procedure in terms of overall noise and indicated efficiency across the plane $1-2-3-4 \ldots . . \ldots \ldots . . . . .$. 
6 Results of the selection procedure for choosing an optimum configuration. The optimum case (9) is distinguished in red while configurations that do not comply with the $\mathrm{NO}_{\mathrm{x}}$ constraint are identified in grey. . . . . . . . . . .

7 Time evolution of the liquid film impingement at cylinder walls and piston surface in both considered injector configurations (bottom). Visualization of baseline and optimized sprays at two different instants during the pilot and main injections (top). . . . . . . . . . .

8 Comparison between original (baseline) and optimum (double crown) injector configurations. Differences in terms of cylinder pressure (obtained at the transducer location) and rate of heat release are plotted in a) whereas pressure spectra are presented in b). . . . . . . . .

9 Comparison of the fuel stratification. RoHR contours along the equivalence ratio $(\phi)$ and crank angle degree are plotted for the baseline in a) and for the optimum in b). . . . . . . .

10 Influence of $\mathrm{SoE}_{\text {main }}$ on emissions (noise and $\mathrm{NO}_{\mathrm{x}}$ ) and engine performance (indicated, combustion and thermodynamic efficiencies) in the baseline and the optimum configurations. . . .

\section{List of Tables}

1 Specifications of the real engine being modelled and results from the injection system characterization . . . . . . . . . . . . 3

2 Values of the parameters used in each of the fifteen numerical simulations according to the test plan of the DoE study . . . . . . . . . . .

3 Comparison of the estimated metrics related to the engine performance and emissions. . . . 